\title{
A double-blind trial of chronic cerebellar stimulation in twelve patients with severe epilepsy
}

\author{
GDS WRIGHT, DL MCLELLAN, JG BRICE \\ From the University Department of Medicine and the Wessex Neurological Centre, Southampton General \\ Hospital, Southampton, UK
}

SUMMARY Twelve patients with severe intractable epilepsy were treated by chronic cerebellar stimulation under double-blind conditions for six months. No reduction in seizure frequency occurred that could be attributed to stimulation, though eleven of the patients considered that the trial had helped them. One patient experienced fewer episodes of incontinence during stimulation. Cerebellar stimulation in its present form cannot be recommended for the treatment of severe intractable epilepsy.

Therapeutic effects of cerebellar stimulation in severe epilepsy were first reported by Cooper.' A later report summarised the outcome in a total of 32 patients. ${ }^{2}$ Seizure frequency fell to half or less of the pre-operative rate in 18 patients and nine were regarded as therapeutic failures. One died at operation and four others died subsequently in their sleep. Two of these had not responded to stimulation, one had been free of grand mal and petit mal attacks for the six week period between implantation and death and the response of the fourth was not described. Treatment was uncontrolled and assessment open.

Several other reports ${ }^{3-6}$ have since appeared which have supported the concept that cerebellar stimulation improves epilepsy, although the effect was less pronounced than in Cooper's series. Only one double-blind study ${ }^{7}$ has been performed. This involved five patients, of whom three, on the criteria recommended by Cooper et al, ${ }^{8}$ might not have been expected to respond favourably.

Severe epilepsy has an appreciable morbidity. Mortality is also increased, especially in young adult males. Lennox ${ }^{9}$ quotes an overall death rate of 11.4 in the age group 25-45 compared with a rate of $3 \cdot 1$ in the general population. Therefore it is extremely important to establish whether or not this treatment should be recommended for occasional cases of severe intractable epilepsy. The present uncertainty

Address for reprint requests: Dr DL McLellan, Southampton General Hospital, Shirley, Southampton SO9 4XY, UK.

Received 24 November 1983 and in revised form 22 January 1984. Accepted 30 January 1984 surrounding the long-term effects of chronic implanted stimulators in the brain would preclude the use of this treatment for milder cases.

Epilepsy is known to be influenced by emotional factors and therefore any new treatment must pass the test of a fully controlled study. We have conducted a double-blind, placebo-controlled study of cerebellar stimulation in a group of 12 patients with severe epilepsy, selected according to Cooper's recommendations.

\section{Method}

\section{Patients}

Twelve patients with severe and intractable epilepsy of unknown cause were selected. Their ages ranged from 20 years to 38 years with a mean of 30 years. Their epilepsy was of long duration, with a range of 10 to 32 years and a mean of 20.6 years. At the time of admission to the trial they were considered to be on the best combination of anticonvulsants at optimum dosage and this dosage had not been changed during the previous six months. Their clinical state had been stable for the previous two years. The electroencephalogram in each case contained quantifiable generalised paroxysmal activity, six patients showing additional focal activity in the frontal or temporal regions. CT scanning of the brain showed morphologically normal cerebral hemispheres in every case. All patients had an IQ of $\mathbf{8 0}$ or over (WAIS). Clinical details of their attacks and their medication are summarised in table 1.

The nature and purpose of the trial was carefully explained to the patients, their close relatives, and the physicians in routine charge of their treatment before proceeding to the trial. The protocol was approved by the Ethical Committee of the Southampton University Hospitals. 
Table 1

\begin{tabular}{|c|c|c|c|c|c|}
\hline Name & Age (yr) & Sex & $\begin{array}{l}\text { Duration of epilepsy } \\
\text { in years }\end{array}$ & Seizure type & Medication \\
\hline SB & 24 & $\mathbf{M}$ & 17 & $\begin{array}{l}\text { Grand mal } \\
\text { Complex absence } \\
\text { Petit mal }\end{array}$ & $\begin{array}{l}\text { Phenytoin } \\
\text { Carbamazepine }\end{array}$ \\
\hline $\mathbf{J N}$ & 27 & $\mathbf{M}$ & 18 & $\begin{array}{l}\text { Grand mal } \\
\text { Atonic seizure } \\
\text { Absences } \\
\text { Myoclonic jerks }\end{array}$ & $\begin{array}{l}\text { Phenytoin } \\
\text { Carbamazepine } \\
\text { Sodium valproate }\end{array}$ \\
\hline MS & 20 & $\mathbf{M}$ & 10 & Complex partial & $\begin{array}{l}\text { Phenytoin } \\
\text { Sodium valproate } \\
\text { Phenobarbitone }\end{array}$ \\
\hline KD & 26 & $\mathbf{M}$ & 19 & $\begin{array}{l}\text { Grand mal } \\
\text { Atonic seizures } \\
\text { Petit mal }\end{array}$ & $\begin{array}{l}\text { Phenytoin } \\
\text { Carbamazepine } \\
\text { Primidone } \\
\text { Ethosuximide }\end{array}$ \\
\hline EP & 34 & $\mathbf{M}$ & 32 & $\begin{array}{l}\text { Grand mal } \\
\text { Atonic seizures } \\
\text { Complex partial }\end{array}$ & $\begin{array}{l}\text { Phenytoin } \\
\text { Carbamazepine } \\
\text { Sodium valproate }\end{array}$ \\
\hline $\mathbf{A P}$ & 38 & $\mathbf{M}$ & 26 & $\begin{array}{l}\text { Atonic seizures } \\
\text { Absences }\end{array}$ & $\begin{array}{l}\text { Phenytoin } \\
\text { Carbamazepine } \\
\text { Sodium valproate }\end{array}$ \\
\hline EK & 34 & $\mathbf{M}$ & 14 & $\begin{array}{l}\text { Complex partial/ } \\
\text { Complex absence }\end{array}$ & $\begin{array}{l}\text { Phenytoin } \\
\text { Sodium valproate } \\
\text { Ethosuximide }\end{array}$ \\
\hline MD & 31 & $\mathbf{M}$ & 21 & $\begin{array}{l}\text { Grand mal } \\
\text { Atonic seizures } \\
\text { Complex partial }\end{array}$ & $\begin{array}{l}\text { Carbamazepine } \\
\text { Sodium valproate } \\
\text { Phenobarbitone }\end{array}$ \\
\hline SC & 24 & $\mathbf{M}$ & 17 & $\begin{array}{l}\text { Grand mal } \\
\text { Atonic seizures } \\
\text { Absences }\end{array}$ & $\begin{array}{l}\text { Phenytoin } \\
\text { Carbamazepine } \\
\text { Primidone }\end{array}$ \\
\hline KL & 25 & $\mathbf{F}$ & 24 & $\begin{array}{l}\text { Grand mal } \\
\text { Partial seizures }\end{array}$ & $\begin{array}{l}\text { Phenytoin } \\
\text { Sodium valproate } \\
\text { Phenobarbitone }\end{array}$ \\
\hline BB & 38 & $\mathbf{F}$ & 29 & $\begin{array}{l}\text { Grand mal } \\
\text { Complex partial } \\
\text { Myoclonic jerks }\end{array}$ & $\begin{array}{l}\text { Phenytoin } \\
\text { Carbamazepine } \\
\text { (Acetazolamide) }\end{array}$ \\
\hline JL & 37 & $\mathbf{M}$ & 20 & $\begin{array}{l}\text { Complex partial/ } \\
\text { Complex absence }\end{array}$ & $\begin{array}{l}\text { Carbamazepine } \\
\text { Clonazepam }\end{array}$ \\
\hline
\end{tabular}

\section{Implantation of stimulation equipment}

Under general anaesthesia, two 8-button electrode pads with an electrode surface area of $32 \mathrm{~mm}^{2}$ (Avery Laboratories Inc) were placed on the upper surface of the cerebellum through bilateral enlarged occipital burr holes. They were positioned parasagittally, approximately $2 \mathrm{~cm}$ from the mid-line on each side. The buttons on the pads were wired in pairs, the first or most rostral pair being connected to the third pair. The current path was therefore in the long axis of the electrode pad. The electrode leads were taken subcutaneously down each side of the neck to two separate receivers placed in pockets in the anterior chest wall or the axillae. A small biopsy was taken from the left cerebellar hemisphere underlying the burr hole during this operation. The access resistance of each electrode was measured and the implanted apparatus calibrated before the incisions in the chest wall were closed. ${ }^{10}$

\section{Stimulation parameters}

The implanted receivers were activated by specially modified transmitters (Avery Laboratories Inc) carried in a holster under the patients' clothing. Two wire antennae, connected to the transmitter, were positioned over each of the implanted receivers so that each electrode could be activated individually if necessary. The receivers delivered capacitatively-coupled pulses of alternating polarity. The transmitters were adjusted to provide a mean peak current of $7 \mathrm{mmA}$ at the electrodes. This value was selected as being similar to that used by Cooper ${ }^{8}$ and, therefore, most likely to produce a therapeutic result. As in other reported series $^{36^{-8}}$ a frequency of 10 cathodal pulses per second (pps) at each electrode was used. In two patients, a mean peak current of $5 \mathrm{~mA}$ was selected because higher levels could be detected by the patients. One patient was considered to show reduction in the amplitude of somatosensory evoked potentials during one recording session after bursts of stimulation at $200 \mathrm{pps}$ and $5 \mathrm{~mA}$ which was therefore chosen as the current for treatment in this case. ${ }^{11} 12$ However, on other occasions, no alteration in evoked potential amplitude could be demonstrated in this patient using bursts of stimulation at 20 pps over the range 1-9 $\mathrm{mA}$. Finally, in one patient a mean peak current of only $1 \mathrm{~mA}$ could be achieved on one side of the cerebellum for technical reasons. These results are summarised in table 2 .

Stimulator function was checked daily by the patient, by holding the antennae near a radio receiver, when a buzzing sound should have been heard. The stimulators were modified internally by the manufacturer so that this sound would occur whether or not the radio frequency out-put was activating the patients' implanted receivers. In practice, there were three modes of stimulation: (1) Continuous stimulation (CONT), alternating from one cerebellar 
Table 2

\begin{tabular}{lllll}
\hline & $\begin{array}{l}\text { Mean peak } \\
\text { current }\end{array}$ & Phase sequence & \\
\hline SB & 5 mA & Int & Off & Cont \\
JN & 7 mA & Off & Int & Cont \\
MS & 5 mA & Off & Cont & Int \\
KD & 7 mA & Cont & Int & Off \\
EP & 7 mA & Cont & Off & Int \\
AP & 7 mA & Cont & Int & Off \\
EK & 7 mA & Cont & Int & Off \\
MD & 5 mA & Off & Cont & Int \\
SC & 7 mA & Int & Cont & Off \\
KL & 7 mA & Int & Cont & Off \\
BB & $7 \mathrm{~mA}$ & Cont & Int & Off \\
JL & 1 mA & Cont & Off & Int \\
\hline
\end{tabular}

hemisphere to the other every minute. (2) Intermittent contingent stimulation (INT), when concurrent stimulation of both cerebellar hemispheres occurred whilst the "seizure button" on the transmitter was depressed and for two minutes after it was released. (3) No stimulation (OFF), when no stimulation occurred to either hemisphere at any time.

\section{Plan of the trial}

The trial was divided into three phases, each lasting two months. Patients received two months of continuous stimulation, two months of contingent stimulation and two months in which there was no stimulation. The sequence of the phases was randomly allocated and the code was not broken until the trial had been completed. Patients were instructed to press the button on the receiver during an aura, if one occurred, or failing that after an attack. Staff members and parents were asked to press it during any attack they observed. These practices were carried out throughout the trial. In each case, the first phase of the trial was begun several months after implantation when the individual had returned to his or her pre-operative siezure frequency. If the patient's equipment failed or some other complication noted in table 3 occurred during any phase of the trial, that phase was abandoned and re-started. If the complication had altered the frequency of attacks, resumption of the trial was delayed until the patient had resumed a stable clinical state. The phase order of each patient is shown in table 2 .
The external apparatus was checked frequently and the stimulus artefact, an indirect measure of the integrity of the implanted apparatus, was regularly measured. Any faults that occurred could be quickly rectified and these tests provided a measure of confirmation that the patients were receiving stimulation at the intended level. ${ }^{10}$

\section{Assessment}

Patients recorded their own seizures and independent seizure charts were kept by hospital staff or the patient's family. The individual was more likely to record the minor seizures and be unable to record the major ones. The convers was true for the observer. Therefore, major seizures recorded by the observer, but not by the patient, were added to the patient's own record. Before surgery and at the end of each phase of the trial, each patient was assessed clinically by two independent consultant neurologists who were not involved in the trial or the patient's routine management. Their impressions were recorded. Each patient was also assessed on these occasions by a clinical psychologist. A consultant psychiatrist reviewed the patients pre-operatively and at the finish of the trial. CSF samples and 24-hour EEG recordings were taken at regular intervals during the course of the trial and the results of these latter assessments will be the subject of a separate communication.

\section{Results}

\section{SEIZURE RECORDS}

The total number of seizures recorded in individual patients in the different phases of the trial are shown in table 4. The totals in each group refer to an equivalent 56 day period. One patient, SB, had so many seizures in a 24-hour period that he only charted those occurring between $12.00 \mathrm{hrs}$. and $18.00 \mathrm{hrs}$.

Three patients were difficult to assess numerically in the same way as the other nine. One, JN, suffered prolonged periods of confusion associated with absence attacks and myoclonic jerks which were difficult to quantify but they did not appear to alter during the three phases. There was no significant difference in his recorded grand mal and atonic seiz-

Table 3

\begin{tabular}{lllr}
\hline & Morbidity & Total nights \\
in hospital
\end{tabular}


Table 4 Total of seizures in each phase of the trial

\begin{tabular}{|c|c|c|c|}
\hline Patient & No stimulation & Continuous & Contingent \\
\hline $\begin{array}{l}\text { SB } \\
\text { JN }\end{array}$ & \multicolumn{2}{|c|}{ Not quantifiable } & 355 \\
\hline MS & 93 & 83 & 63 \\
\hline KD & 84 & 48 & 65 \\
\hline EP & 26 & 34 & 21 \\
\hline AP & 162 & 226 & 226 \\
\hline EK & 83 & 66 & 71 \\
\hline MD & 47 & 52 & 61 \\
\hline SC & \multicolumn{3}{|c|}{ Not fully quantifiable } \\
\hline $\mathbf{K} \mathbf{L}$ & 33 & 1 & 35 \\
\hline BB & 344 & 384 & 247 \\
\hline JL & \multicolumn{3}{|c|}{ Not fully quantifiable } \\
\hline
\end{tabular}

ures. One patient, SC, became uncooperative during the trial and refused to wear the stimulating equipment at times or record his seizures. There was no significant difference in the major seizures in the different phases as recorded by the staff at the epilepsy centre where he lived. The third patient, $\mathrm{JL}$, who lives at home, mislaid some of his records and so we have incomplete data.

In the remaining nine there was no statistically significant difference between their treatment group and the no-stimulation phase, using the Wilcoxon matched-pairs signed-ranks test.

PATIENTS' ASSESSMENT OF THE EFFECTIVENESS OF CEREBELLAR STIMULATION

All patients but one, SC, felt better for cerebellar stimulation, thought it had helped them and wished to continue with it after the trial had finished. Only five patients chose one phase as being different from the others. Two chose the continuous phase, one chose the contingent phase and two chose the phase of no-stimulation. Only one patient's assessment of the best phase agreed with our assessment and in this case the phase of no-stimulation was his best. Eleven of the patients reported that the seizure button was helpful in all three phases, but none singled out one phase as being better than the others in this respect. One patient, KL, stated, "Stimulation has revolutionised my life" therefore enabling her to take a job outside the centre for epilepsy where she lived.

In only one patient were there repeatable benefi- cial effects in response to stimulation itself. This consisted of a slight reduction in the frequency of episodes of incontinence with contingent stimulation associated, more questionably, with a shift of seizures from waking hours to hours of sleep with continuous stimulation as shown in table 5. This patient (MS) felt so much more confident that he resorted to using public transport and to going out alone, with the approval of his parents. Subsequent single-blind adjustments of stimulation strength and frequency in his patient have continued to suggest a slight reduction in the incidence of incontinence when receiving continuous plus contingent stimulation.

\section{CLINICAL ASSESSMENT}

The two independent neurologists tended to concur with the patients' own assessment of their treatment and therefore were left with the impression that cerebellar stimulation had probably been helpful to the group as a whole. Psychiatric assessment confirmed that no adverse psychiatric sequelae could be detected as a result of the stimulation trial. Psychometry did not reveal any major changes in any patients in any of the phases of the trial.

\section{ADVERSE EFFECTS}

The morbidity associated with this procedure was not inconsiderable. Six patients required more than one operation. Two patients had a post-operative wound infection, one of which settled with antibiotics; the other patient eventually required total removal of all the implanted apparatus. She was later reimplanted. Most patients experienced temporary swelling over one or both receiver sites, presumably due to CSF accumulation but this settled without further surgery. In one patient CSF began to accumulate several weeks after implantation and lead wires on one side had to be re-routed. The implanted apparatus failed in only one patient; both recievers developed faults and needed replacement. The complications are summarised in table 5 which also includes the total number of days each patient spent in the neurological centre during the trial.

\section{LATE DEATHS}

After the trial had finished, one patient was found dead by his bed, presumably as a result of a seizure.

Table 5 Record of seizures and incontinence in patient MS (figures adjusted to compare rates for periods of 56 days in each phase)

\begin{tabular}{|c|c|c|c|c|c|c|c|}
\hline Phase of trial & $\begin{array}{l}\text { Nocturnal } \\
\text { seizures }\end{array}$ & $\begin{array}{l}\text { Times } \\
\text { incontinent } \\
\text { at night }\end{array}$ & $\begin{array}{l}\text { Daytime } \\
\text { seizures }\end{array}$ & $\begin{array}{l}\text { Times } \\
\text { incontinent } \\
\text { during the day }\end{array}$ & $\begin{array}{l}\text { Days with no } \\
\text { seizures }\end{array}$ & $\begin{array}{l}\text { Days with no } \\
\text { incontinence }\end{array}$ & $\begin{array}{l}\text { Stimulation } \\
\text { pattern }\end{array}$ \\
\hline $\begin{array}{l}\text { I } \\
\text { II } \\
\text { III }\end{array}$ & $\begin{array}{l}24 \\
50 \\
37\end{array}$ & $\begin{array}{r}12 \\
17 \\
2\end{array}$ & $\begin{array}{l}69 \\
33 \\
26\end{array}$ & $\begin{array}{l}9 \\
5 \\
5\end{array}$ & $\begin{array}{l}41 \\
52 \\
47\end{array}$ & $\begin{array}{l}51 \\
54 \\
53\end{array}$ & $\begin{array}{l}\text { None } \\
\text { Continuous } \\
\text { Contingent }\end{array}$ \\
\hline
\end{tabular}


He was not receiving cerebellar stimulation at this time. The necropsy findings have been published in detail elsewhere. ${ }^{13}$ There was no evidence that cerebellar stimulation contributed in any way to this event.

\section{Discussion}

The results of this trial of cerebellar stimulation are disappointing but are in agreement with the only other double-blind trial that has been published to date. ${ }^{7}$ The contrast between the two double-blind studies and the enthusiastic claims of the uncontrolled studies is most interesting. Gilman et $a^{3}$ noted improvement in the character or frequency of the seizures in five of the six patients they studied, although only two were sufficiently improved to allow vocational rehabilitation. A single-blind study was conducted in three of the patients but no difference in seizure frequency was seen between periods when the stimulator was on or off. Fenton et $a^{4}$ found no appreciable change in the frequency of major seizure in the one patient they studied but did show a significant reduction in the number of drop attacks and petit mal seizures. Dow et al $^{5}$ reported improvement in three patients with intractable epilepsy although one waited for 18 months to begin stimulation after implantation because of spontaneous post-operative improvement. Levy and Auchterlinie ${ }^{6}$ reported on chronic cerebellar stimulation in six cases of intractable epilepsy. Two patients were greatly improved and a third showed a $50 \%$ reduction in her major seizures although her minor seizures remained at a similar frequency. The present authors found no improvement in an open study of a girl with Lafora body disease but she received cerebellar stimulation for a few days only. ${ }^{15}$ In all the studies to date, the patients' and relatives' reactions to treatment have been similarly favourable. It is possible that our patients' claim that their epilepsy had improved with stimulation reflected changes that we had not measured. We did not attempt, for example, to measure the duration of clinical attacks nor the severity and duration of post-ictal confusion, both features that were mentioned by several patients as having shown improvement. However, the patients were unable by these criteria to identify the stimulation phases of the trial as better than the no-stimulation phases. Similarly, those who were enthusiastic about the power of the "seizure button" to abort their attacks did not distinguish between the phase of the trial when it was working and the phases in which it was disconnected.

These observations have left us with the impression that the nature of this treatment is such as to provide a powerful placebo effect. Patients with epilepsy are aware that their symptoms are caused by an "electrical disturbance" of brain function and on carrying an electrical transmitter with a button they can activate at will, they report feelings of confidence and of being in control of their condition, which probably explains their acceptance of the treatment despite its inconveniences and the necessity for fairly major surgery.

The fact that improved confidence can make such an impact upon the patients' lifestyle certainly justifies efforts to rehabilitate patients with epilepsy even when the frequency of their seizures cannot be improved.

It may be that the patients studied in the group reported here were refractory to this form of treatment, or that different frequencies or strengths of stimulation would have produced a different result. Furthermore, the siting of the electrodes on the cerebellar surface may not have been optimal. However, the type of patients, the electrode configuration and siting and the stimulation variables were all chosen in the light of previous reports as being most likely to produce benefit. Further experimental work in primates is indicated to establish more precisely the targets in the cerebellum at which stimulation should be directed.

These patients would have constituted a severe test for any anticonvulsive treatment and it would therefore be wrong to assume that cerebellar stimulation would have no effect in milder cases. However, the morbidity of the procedure and the uncertain long-term effects of chronic electrical stimulation make this form of treatment unsuitable for milder cases at present. From the evidence of our experience in this trial, cerebellar stimulation cannot be recommended as a treatment for severe epilepsy, particularly for the occasional isolated case. In our view, cerebellar stimulation for epilepsy should not be performed except under placebo-controlled trial conditions.

We thank the patients and their relatives for their cooperation and $\mathrm{Mr}$ Roger Avery of Avery Laboratories for his continued interest and support for this study. GDSW was supported by a grant from the Medical Research Council. We are very grateful for the unstinting help and encouragement of $\mathrm{Dr}$ Jolyon Oxley (Chalfont Centre for Epilepsy) and Dr Richard Grant (David Lavis Centre, Cheshire).

\section{References}

' Cooper IS. Effect of chronic stimulation of anterior cerebellum on neurological disease. Lancet 1973;1:206. 
${ }^{2}$ Cooper IS, Riklan M, Amin I, Cullinan T. A long-term follow-up study of cerebellar stimulation for the control of epilepsy. In: Cooper IS, ed. Cerebellar Stimulation in Man New York: Raven Press, 1978:19-23.

${ }^{3}$ Gilman S, Dauth GW, Tennyson VM, Krmzner LT, Defendini R, Correll JW. Clinical, morphological, biochemical, and physiological effects of cerebellar stimulation. In: Hambrecht FT, ed. Functional Electrical Stimulation: Applications in Neural Prostheses New York: Marcel Dekker, 1977:191-266.

${ }^{4}$ Fenton GW, Fenwick PBC, Brindley GS, Falconer MA, Polkey CH, Rushton DN. Chronic cerebellar stimulation in the treatment of epilepsy: a preliminary report. In: Penry JK, ed. Epilepsy, The Eighth International Symposium New York: Raven Press, 1977:333-40.

${ }^{5}$ Dow RS, Smith W, Maukonen L. Clinical experience with chronic cerebellar stimulation in epilepsy and cerebral palsy. Electroencephalogr Clin Neurophysiol 1977;43:906.

- Levy LF, Auchterlonie WC. Chronic cerebellar stimulation in the treatment of epilepsy. Epilepsia 1979;20:235-45.

${ }^{7}$ Van Buren JM, Wood JH, Oaly J, Hambrecht F. Preliminary evaluation of cerebellar stimulation of double-blind stimulation and biological criteria in the treatment of epilepsy. $J$ Neurosurg 1978;48:407-16.

${ }^{8}$ Cooper IS, Amin I, Riklan M, Waltz JM, Poon TP. Chronic cerebellar stimulation in epilepsy. Arch Neurol 1976;33:559-70.

${ }^{9}$ Lennox WG. Epilepsy and Related Disorders Boston: Little, Brown \& Company, 1960:1017.

${ }^{10}$ McLellan DL, Wright GDS, Renouf F. Calibration of clinical cerebellar and deep brain stimulation systems. J Neurol Neurosurg Psychiatry 1981;44:392-6.

" Upton ARM, Cooper IS. Some neurophysiological effects of cerebellar stimulation in man. Can J Neurol Sci 1976;3:237-54.

12 Larson J, Sances A, Hemmy DC, Millar EA, Walsh PR. Physiological and histological effects of cerebellar stimulation. Appl Neurophysiol 1977/78;40:160-74.

${ }^{13}$ Wright GDS, Weller RO. Biopsy and post-mortem findings in a patient receiving cerebellar stimulation for epilepsy. J Neurol Neurosurg Psychiatry 1983;46:266-73.

14 Wright GDS, McLellan DL. Absence of clinical or physiological changes during short-term cerebellar stimulation in a patient with Lafora body disease. $J$ Neurol Neurosurg Psychiatry 1981;44:364-6. 